\title{
Carvão: a chave de uma porta do mundo
}

\author{
MARIA JOSÉ ViLlares BARRAL VILlas BoAs \\ Universidade Federal do Rio de Janeiro, Rio de Janeiro, Rio de Janeiro, Brasil \\ zezabarral@gmail.com
}

DOI 10.11606/issn.2316-9133.v29i2pe179760

"Quando a gente pinta o rosto, a gente se abre", contou-me um integrante da Associação Cultural Nego Fugido, da comunidade quilombola de Acupe, distrito de Santo Amaro, no Recôncavo Baiano, em março de 2020. Em 2015, o mesmo interlocutor rejeitou ser identificado em uma imagem. Ao se ver na fotografia do Nego Fugido, grupo que faz parte desde criança, ele me contradisse: "Esse aí não sou eu, não". Eu aceitei a negação desconfiada, e só compreendi melhor o que ele estava me dizendo anos depois. Desde julho de 2012, período de minhas primeiras incursões no campo da pesquisa etnográfica, entendi que havia no Nego Fugido uma experiência de transformação ritualística quando os interlocutores entravam em contato com os objetos e as substâncias que configuram a performance cultural.

Em linhas gerais, no Nego Fugido é uma performance cultural que conta a história de escravos fugidos que lutaram para comprar sua liberdade através da carta de alforria. As figuras que compõem a narrativa são as nêgas, que são os escravos fugidos; os caçadores, algozes que caçam as nêgas e as vendem pelas ruas; o capitão do mato, figura que controla os caçadores e está sob comando do; rei, figura identificada como o dono dos escravos; os guardas, que realizam a proteção do monarca; e a madrinha, protetora responsável por apaziguar os confrontos.

O carvão moído misturado ao óleo de cozinha pintado no rosto das nêgas e dos caçadores, a anilina vermelho sangue excretada da boca, o charuto baforado pelos caçadores e pelo capitão do mato, o cheiro de espoleta das espingardas adaptadas, a poeira levitando das ruas de terra batida, o uso das saias de folhas secas de bananeira, o som dos atabaques tocando alujá, guiando os caminhos da performance pelas ruas da vila, evocando cantos e danças, etc. ${ }^{1}$ Muitas relações emanavam ali. Dentre elas, a relação entre o visível e o invisível que os corpos, em contato com esses elementos e substâncias, agenciam em torno de si.

\footnotetext{
${ }^{1}$ Alujá é um toque de fundamento de religiões afro-brasileiras em que o andamento é rápido e dança acelerada. É realizado para chamar o orixá Xangô, popularmente conhecido como o deus da justiça, do fogo e do trovão;
} 
O Nego Fugido vivo nos corpos é tomado pela catarse do sofrimento e de luta. As nêgas vivem suas fugas, resistem ao aprisionamento que levará a suas mortes. Elas gritam dor, revolta e desespero; se jogam no chão em agonia, como se estivessem em convulsão. Acorrentadas, gemem e clamam para que alguém venha ajudar. Tentam ressuscitar umas às outras, choram a perda de suas companheiras, imploram por liberdade e por dinheiro aos passantes. Dilaceradas, unem-se contra as figuras dos opressores em um grande confronto de dança, empurrões e golpes de maculelê que arrematam a performance.

O uso do negrume, através do carvão e do óleo, na performance cultural do Nego Fugido é uma espécie de autorização. $O$ ato é uma comunicação feita aos ancestrais para que eles vivam novamente nos corpos de seus descendentes. Pintar o rosto é uma permissão dada pelos participantes, todos nascidos em Acupe, para que as entidades venham ao seu encontro: O carvão é um elemento ritual usado para acionar uma espécie de transe, e sua existência física opera como agente social na relação com os atores visíveis e invisíveis do Nego Fugido. Apresenta-se como coisa que viabiliza a relação entre as pessoas (GELL 2018) e seus ancestrais. Como índice, o carvão anuncia que naquele momento e espaço, o corpo está sendo coabitado - mesmo que, em muitos casos, isso não seja pretendido pelos participantes. Algumas lideranças religiosas da comunidade não relacionam o Nego Fugido às entidades, não identificam que a performance faça parte de liturgia do candomblé, e por vezes preferem não falar sobre o assunto.

Em escritos dissertativos propus pensar sobre prática de pintar o rosto de carvão sob outra chave: um movimento de hiperracialização dos corpos, uniformizando marcadores de diferenciação social de gênero (VILLAS BOAS 2016). Entendia que, aproximando-me aos sentidos dados pelas crianças ao Nego Fugido e como o Nego Fugido é vivido em seus corpos, acionar a pintura poderia ser um modo liminar em que meninos e meninas assumiram a mesma identidade na figura de nêgas, para vivê-lo como um ritual de passagem.

Nesse ensaio foto-etnográfico, tentando compreender o processo de transformação pelo qual passam os participantes do Nego Fugido todos os domingos de julho há mais de um século, proponho uma interpretação do Nego Fugido como uma narrativa quimérica. Pondero que a construção da imagem ultrapassa a leitura interpretativa do que é dado ao olhar. A imagem está em uma relação dinâmica de constituição do campo, aquilo que está circunscrito no enquadramento, na escolha do plano, ângulo, etc. Com o extra-campo, o conjunto complexo de signos que é excluído da imagem. A eficácia das imagens quiméricas é intensificada à medida que exerce seu potencial de mobilizar. Uma conexão entre o que é visível e invisível, como mediadora de lados de um mesmo mundo (SEVERI, LAGROU 2013). A "representação quimérica” abraça consigo o que Severi e Lagrou (2013) trataram como abstração: aquilo que pode ser visualizado, mas não se dá a ver por nós observadores.

em ioruba, a palavra significa "perfuração", e remete ao mito que diz que Xangô teria perfurado a terra com um poderoso trovão, entrado e se transformado em divindade (CARDOSO 2006). 
Toda imagem múltipla que, associando em uma só forma índices visuais provindos de seres diferentes (um pássaro e um ser humano, uma serpente e um jaguar, ou um lobo e um leão marinho...), provoca uma projeção por parte do olho, que faz surgir uma imagem implicando ao mesmo tempo a presença destes seres diferentes. Uma representação plural onde o que é dado a ver apela necessariamente à interpretação do que é implícito. Esta parte invisível da imagem se encontra totalmente engendrada a partir de índices dados em um espaço mental. Um único princípio subjaz à estrutura destas representações: a condensação da imagem em alguns traços essenciais supõe a interpretação da forma por projeção, e portanto, por preenchimento das partes faltantes (SEVERI, LAGROU 2013: p.11$12)$.

No Nego Fugido, a performance cultural deu a ver e escondeu, durante todos esses anos de existência, justamente o que queria que fosse visto e escondido, para se manter vivo. $\mathrm{O}$ uso do carvão deixa rastros contraditórios. Portas se abrem e se fecham a todo tempo. $\mathrm{O}$ segredo e o mistério foram e ainda são estratégias de existência étnica, política e social para as culturas afrodiaspóricas em uma sociedade hierarquizada racialmente. Hoje o Nego Fugido reivindica dar a ver ele mesmo, sem mediações. Somente o olhar sobre o que está implícito, sobre o invisível, vê a sua transformação em curso.

Como movimento quimérico de tentar preencher as partes que faltam, as imagens desse ensaio também convocam a transformação do olhar sobre o corpo, para que vejamos a experiência deste frente aos acontecimentos rituais. Dentre eles, a relação enredada no contato com o carvão. O que é dado a ver são elementos estéticos que conferem plasticidade a performance cultural. $\mathrm{O}$ acréscimo necessário ao nosso olhar para completar o que vemos diz respeito ao ver ancestral. Assim como os corpos dos integrantes se abrem, nossos olhos são convocados a se abrir para uma percepção cognitiva de que outras relações são engendradas ali, transformando aquela experiência corporal em uma vivência metafísica, histórica e transcendental. $\mathrm{O}$ carvão sobre o rosto dá vida à ancestralidade, e no campo perceptivo, evidencia a conexão entre os seres e as coisas.

O negrume transforma o corpo, e uma pessoa é ao mesmo tempo ela mesma e Outro ancestral, como me disse em outras palavras aquele integrante que fotografei em 2015. No fluxo de ver o visível e o invisível, o carvão opera como "coisa" visível, um índice que permite a "abdução da agência" (GELL, 2018). Ou seja, permite-nos inferir, no regime da visualidade que nos cabe, que existe uma relação entre a substância, os corpos e os seres invisíveis. No Nego Fugido, assim como nesse ensaio, o carvão é chave para abertura dos corpos dos integrantes da performance e de nossos olhos, portas de conexão entre o visível e o invisível, partes de um mesmo mundo.

\section{Referências Bibliográficas}


CARDOSO, Angelo Nonato Natale. (2006). A linguagem dos tambores. Tese de doutorado. PPGMUS-UFBA. Salvador.

GELL, Alfred. (2018). Arte e Agência. Uma teoria antropológica. São Paulo: Udu Editora. PINTO, Monilson dos Santos Rastelli. (2014). Nego fugido: o teatro das aparições. $164 \mathrm{f}$. Dissertação (mestrado) - Universidade Estadual Paulista "Julio de Mesquita Filho", Instituto de Artes.

SEVERI, Carlo; LAGROU, Els. (Orgs.).(2013). "Introdução”. In: Quimeras em diálogo: grafismo e figuração nas artes indígenas. Rio de Janeiro: 7Letras, 2013.

SEVERI, Carlo. (2013). “O espaço quimérico. Percepção e projeção nos atos de olhar”. In: SEVERI, Carlo; LAGROU, Els. (Orgs.). Quimeras em diálogo: grafismo e figuração nas artes indígenas. Rio de Janeiro: 7Letras, 2013.

VILLAS BOAS, Maria José Villares Barral. (2016). \{Per[for(mar)]\}: imagens das crianças no Nêgo Fugido, Acupe/BA. Dissertação de Mestrado em Antropologia Social). Brasília: PPGAS/Universidade de Brasília.

Maria José Villares Barral Villas Boas

É mestra em Antropologia pela Universidade de Brasília e doutoranda em Antropologia e Sociologia pelo Instituto de Filosofia e Ciências Sociais da Universidade Federal do Rio de Janeiro.

Recebido em 09/12/2020

Aceito para publicação em 21/12/2020 
VILLAS BOAS | Carvão: a chave de uma porta do mundo | 5
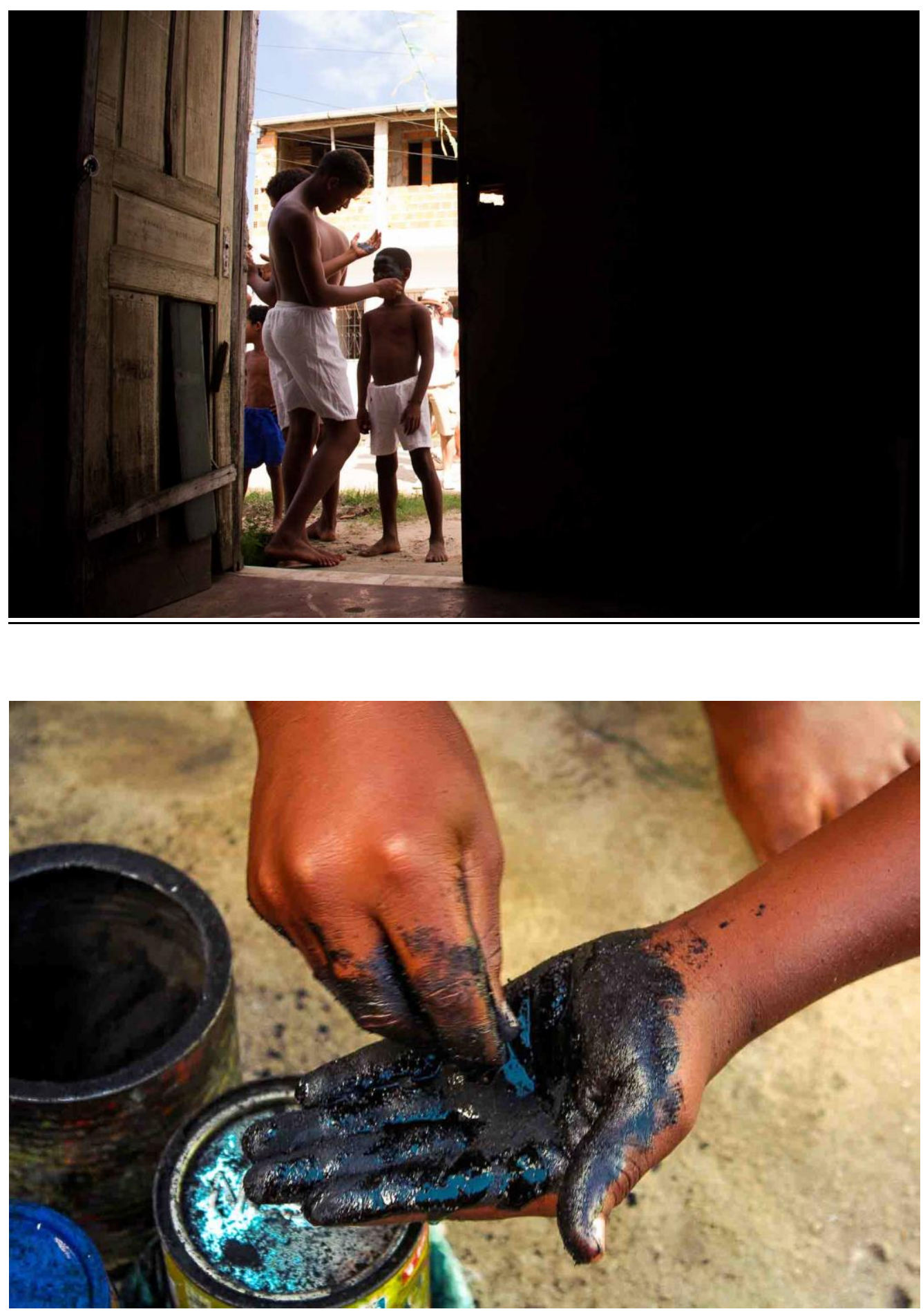
VILLAS BOAS | Carvão: a chave de uma porta do mundo | 6

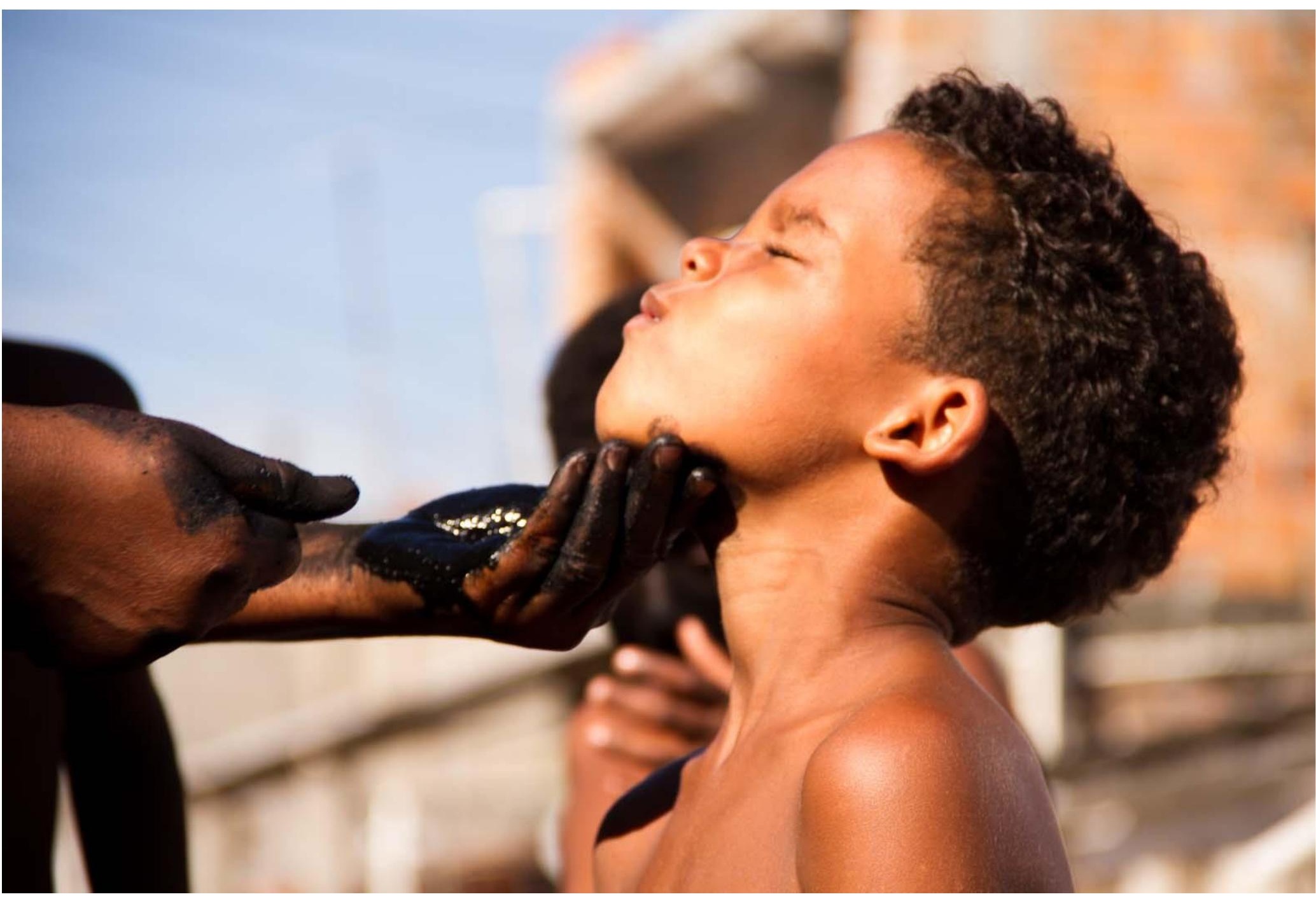


VILLAS BOAS | Carvão: a chave de uma porta do mundo $\mid 7$

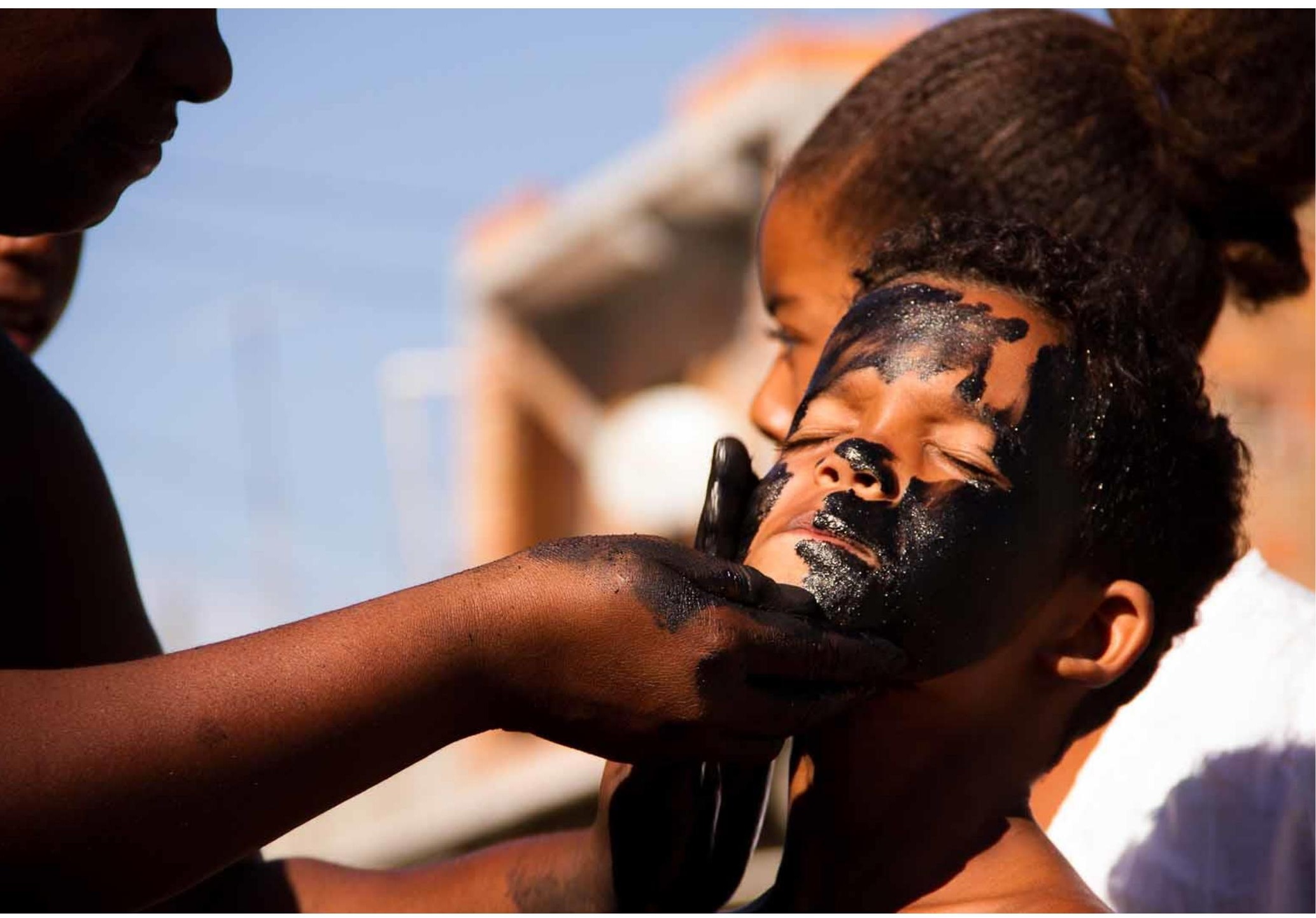


VILLAS BOAS | Carvão: a chave de uma porta do mundo | 8 
VILLAS BOAS | Carvão: a chave de uma porta do mundo | 9
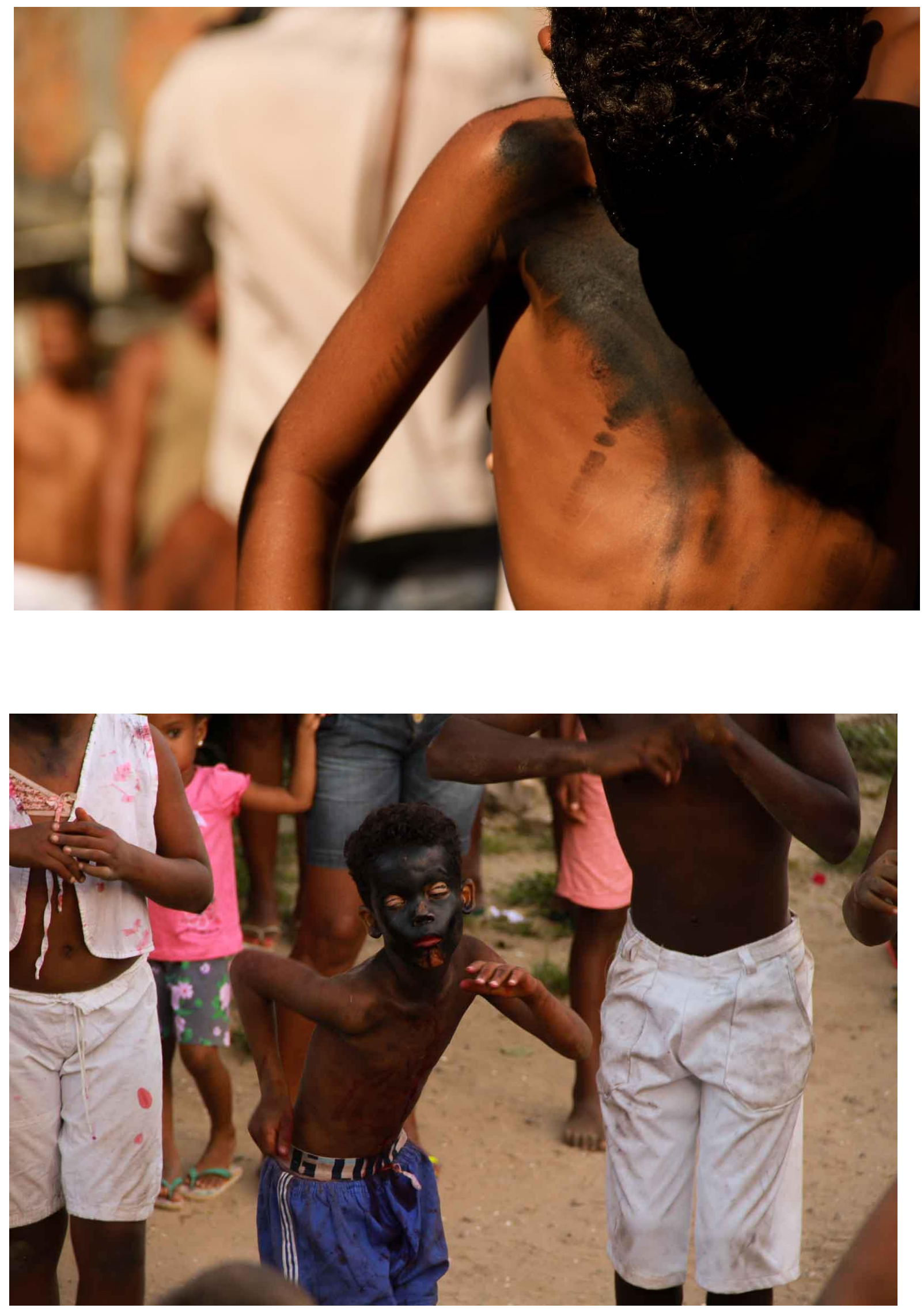
VILLAS BOAS | Carvão: a chave de uma porta do mundo | 10

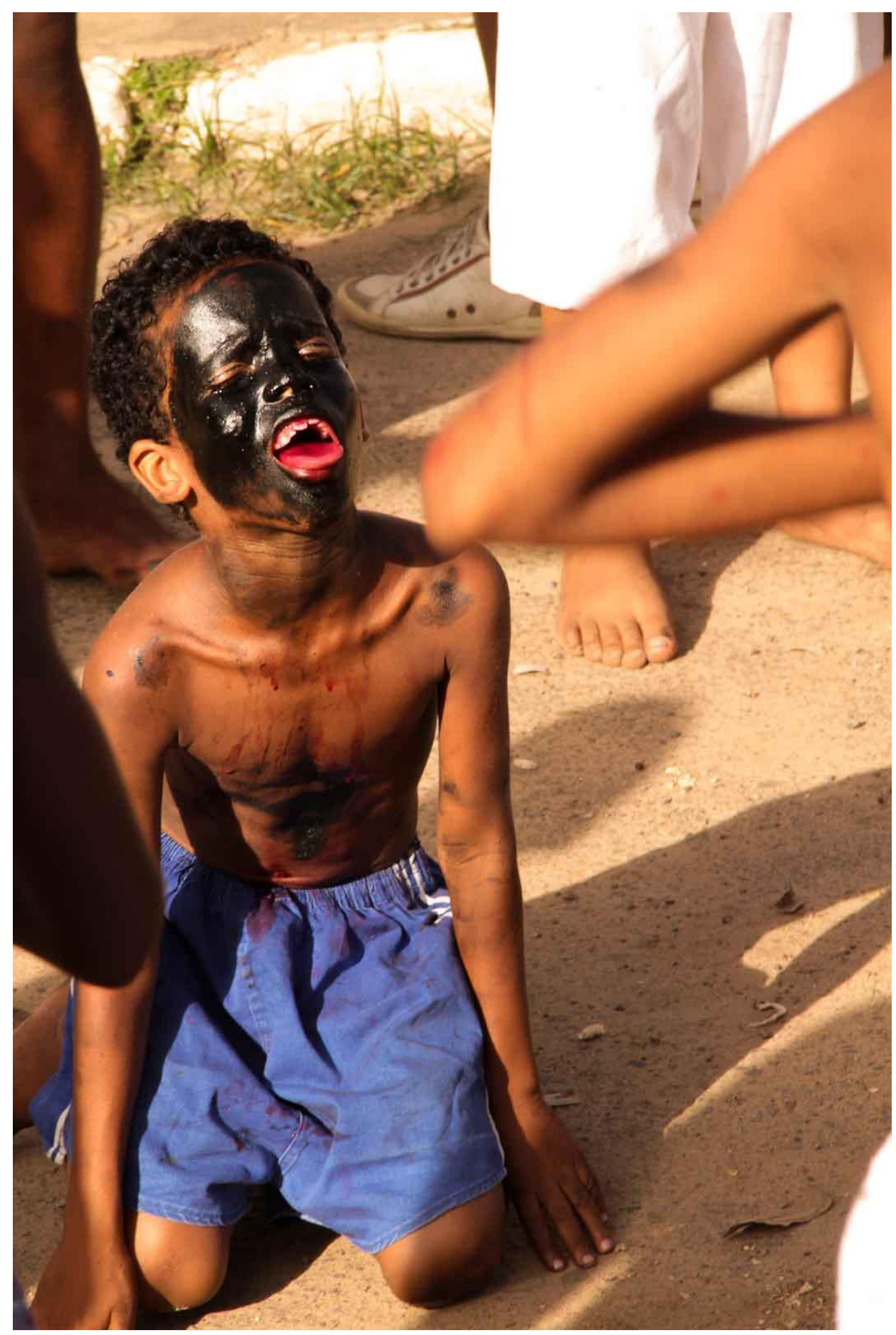


VILLAS BOAS | Carvão: a chave de uma porta do mundo | 11

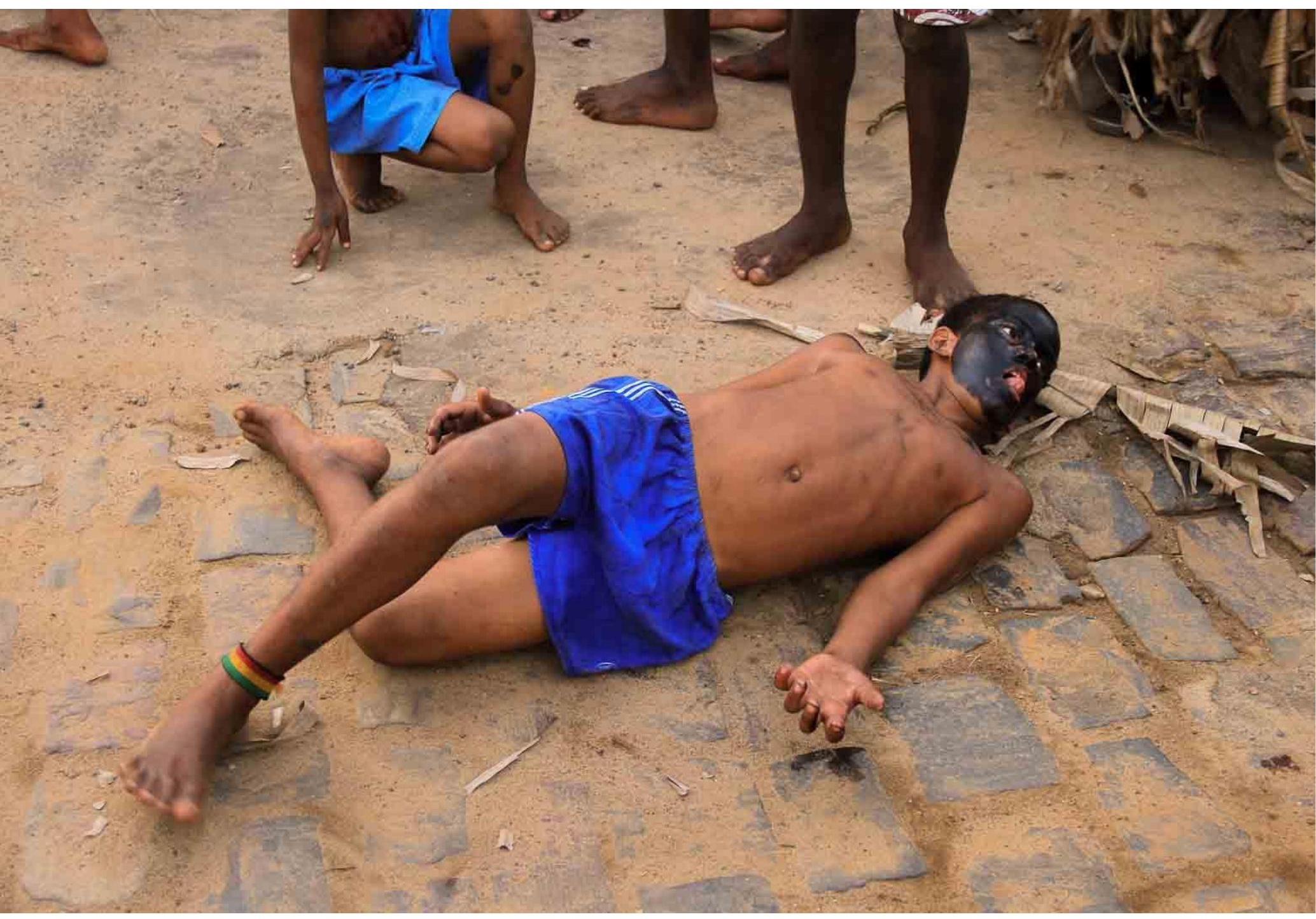


